NASA/TM-2009-215627

\title{
Large Eddy Simulation of Transonic Flow Field in NASA Rotor 37
}

\section{Chunill Hah}

Glenn Research Center, Cleveland, Ohio 


\section{NASA STI Program . . . in Profile}

Since its founding, NASA has been dedicated to the advancement of aeronautics and space science. The NASA Scientific and Technical Information (STI) program plays a key part in helping NASA maintain this important role.

The NASA STI Program operates under the auspices of the Agency Chief Information Officer. It collects, organizes, provides for archiving, and disseminates NASA's STI. The NASA STI program provides access to the NASA Aeronautics and Space Database and its public interface, the NASA Technical Reports Server, thus providing one of the largest collections of aeronautical and space science STI in the world. Results are published in both non-NASA channels and by NASA in the NASA STI Report Series, which includes the following report types:

- TECHNICAL PUBLICATION. Reports of completed research or a major significant phase of research that present the results of NASA programs and include extensive data or theoretical analysis. Includes compilations of significant scientific and technical data and information deemed to be of continuing reference value. NASA counterpart of peer-reviewed formal professional papers but has less stringent limitations on manuscript length and extent of graphic presentations.

- TECHNICAL MEMORANDUM. Scientific and technical findings that are preliminary or of specialized interest, e.g., quick release reports, working papers, and bibliographies that contain minimal annotation. Does not contain extensive analysis.

- CONTRACTOR REPORT. Scientific and technical findings by NASA-sponsored contractors and grantees.

- CONFERENCE PUBLICATION. Collected papers from scientific and technical conferences, symposia, seminars, or other meetings sponsored or cosponsored by NASA.

- SPECIAL PUBLICATION. Scientific, technical, or historical information from NASA programs, projects, and missions, often concerned with subjects having substantial public interest.

- TECHNICAL TRANSLATION. Englishlanguage translations of foreign scientific and technical material pertinent to NASA's mission.

Specialized services also include creating custom thesauri, building customized databases, organizing and publishing research results.

For more information about the NASA STI program, see the following:

- Access the NASA STI program home page at http://www.sti.nasa.gov

- E-mail your question via the Internet to help@ sti.nasa.gov

- Fax your question to the NASA STI Help Desk at $443-757-5803$

- Telephone the NASA STI Help Desk at 443-757-5802

- Write to: NASA Center for AeroSpace Information (CASI) 7115 Standard Drive Hanover, MD 21076-1320 
NASA/TM-2009-215627

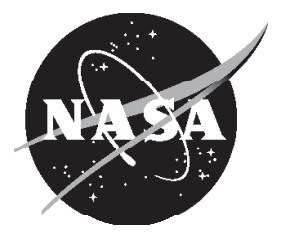

\title{
Large Eddy Simulation of Transonic Flow Field in NASA Rotor 37
}

\author{
Chunill Hah \\ Glenn Research Center, Cleveland, Ohio
}

Prepared for the

47th Aerospace Sciences Meeting

sponsored by the American Institute of Aeronautics and Astronautics

Orlando, Florida, January 5-8, 2009

National Aeronautics and

Space Administration

Glenn Research Center

Cleveland, Ohio 44135 
This work was sponsored by the Fundamental Aeronautics Program at the NASA Glenn Research Center.

Level of Review: This material has been technically reviewed by technical management.

Available from

NASA Center for Aerospace Information

7115 Standard Drive

Hanover, MD 21076-1320
National Technical Information Service 5285 Port Royal Road Springfield, VA 22161

Available electronically at $\underline{\mathrm{http}: / / g l t r s . g r c . n a s a . g o v}$ 


\title{
Large Eddy Simulation of Transonic Flow Field in NASA Rotor 37
}

\author{
Chunill Hah \\ National Aeronautics and Space Administration \\ Glenn Research Center \\ Cleveland, Ohio 44135
}

\begin{abstract}
The current paper reports on numerical investigations on the flow characteristics in a transonic axial compressor, NASA Rotor 37. The flow field was used previously as a CFD blind test case conducted by American Society of Mechanical Engineers in 1994. Since the CFD blind-test exercise, many numerical studies on the flow field in the NASA Rotor 37 have been reported. Although steady improvements have been reported in both numerical procedure and turbulence closure, it is believed that all the important aspects of the flow field have not been fully explained with numerical studies based on the Reynolds Averaged Navier-Stokes (RANS) solution. Experimental data show large dip in total pressure distribution near the hub at downstream of the rotor at $100 \%$ rotor speed. Most original numerical solutions from the blind test exercise did not predict this total pressure deficit correctly. This total pressure deficit at the rotor exit was attributed to a hub corner flow separation by the author. Several subsequent numerical studies with different turbulence closure model also calculated this dip in total pressure rise. Also, several studies attributed this total pressure deficit to a small leakage flow coming from the hub in the test article. As the experimental study cannot be repeated, either explanation cannot be validated. The primary purpose of the current investigation is to investigate the transonic flow field with both RANS and a Large Eddy Simulation (LES). The RANS approach gives similar results presented at the original blind test exercise. Although the RANS calculates higher overall total pressure rise, the total pressure deficit near the hub is calculated correctly. The numerical solution shows that the total pressure deficit is due to a hub corner flow separation. The calculated pressure rise from the LES agrees better with the measured total pressure rise especially near the casing area where the passage shock interacts with the tip clearance vortex and flow becomes unsteady due to this interaction. The LES simulation also calculates the total pressure rise deficit near the hub and it agrees well with the measured data.
\end{abstract}

\section{Introduction}

One of the goals of the NASA Fundamental Aeronautics Program is the assessment of various computational fluid dynamic (CFD) codes now used by NASA and industry in the design and analysis of aircraft, spacecraft, propulsion systems, etc. The goal is to assess the current state of the art of these codes, then to periodically reassess the codes as advances are made in CFD.

Several CFD codes for turbomachinery problems were assessed for the Subsonic Fixed Wing project. The codes were assessed for one or two transonic compressors designed and tested by Reid and Moore (Refs. 1 to 3) around 1978 at NASA Lewis Research Center (now Glenn). Reid and Moore designed four compressors to investigate the effects of blade camber and aspect ratio on compressor performance. The two compressors with low-aspect-ratio blades had the best performance and have since been retested and used for several CFD code assessment projects.

The first compressor was an isolated rotor designated NASA Rotor 37. It was retested by Strazisar and Suder (Refs. 4 and 5) in the 1990s using both aerodynamic surveys and laser anemometry. Their data was used for a CFD blind test case conducted by International Gas Turbine Institute (IGTI) of the American Society of Mechanical Engineers (ASME) in 1994 (unpublished) and for a more detailed but nonblind test case conducted by AGARD (Refs. 6 and 7) in 1997-8.

This paper describes calculations of isolated Rotor 37 flow field made using the H3D code. H3D is a multiblock Navier-Stokes analysis code for turbomachinery developed by Hah (Refs. 8 and 9). Hah is one 
of 10 participants of the 1994 CFD blind test workshop that was sponsored by the International Gas Turbine Institute of the American Society of Mechanical Engineers. Numerical results with a modified two-equation turbulence model were presented during the workshop. Some improvements on the numerical procedures have been implemented on the original code. The flow fields at different operating conditions are calculated again and the calculated flow fields are very similar to the original solutions presented during the original ASME workshop.

The numerical results were further analyzed and published in a separate paper by Hah and Loellbach (Ref. 10). The code has been widely applied to study various transonic compressors since then (Refs. 11 to 13). The numerical results have been compared with available test data from many different transonic compressors. The code has been predicting the characteristics of all the tested compressors fairly well if various uncertainties of measurement are considered. Although absolute values of one-dimensional performance numbers, like total pressure/temperature rise, were not matched exactly, expected differences among different designs were predicted fairly well for design guidance. The code was used to develop swept rotor concept in transonic fan/compressor (Ref. 14). Several attempts have been made to improve the turbulence model in the code. So far, we have not found any turbulence model that performs universally better for the variety of flow fields in different transonic compressors.

A Large Eddy Simulation (LES) capability has been added to the code (Ref. 15). The LES procedure is applied primarily to capture transient characteristics of the compressor flow more realistically. Accurate understanding of unsteady interactions among passage shock, tip leakage vortex, and vortex shedding in a transonic compressor at near stall operation remains one of the challenges for compressor designers.

\section{Test Rotor and Test Facility}

Rotor 37 is a low aspect ratio inlet rotor for a core compressor. It has 36 multiple circular-arc (MCA) blades and a design pressure ratio of 2.106 at a mass flow of $20.19 \mathrm{~kg} / \mathrm{sec}$. It was originally designed and tested at NASA Lewis Research Center (now Glenn) in the late 1970s by Reid and Moore (Refs. 1 and 3). The rotor was retested in a single-stage compressor facility at NASA Glenn by Suder, et al. (Refs. 4 and 5). Radial distributions of static and total pressure, total temperature, and flow angle were measured at two axial stations located $4.19 \mathrm{~cm}$ upstream and $10.67 \mathrm{~cm}$ downstream of the blade hub leading edge, labeled stations 1 and 4 in Figure 1. Detailed laser anemometry measurements were made of the velocity field within the rotor and wake at several axial stations and on five spanwise planes also shown in Figure 1.

The IGTI of ASME sponsored a blind test exercise for turbomachinery CFD codes with this flow field at the 39th International Gas Turbine Conference held in The Hague, Netherlands (unpublished) in 1994. The same test case was later used by the AGARD Propulsion and Energetics Panel Working Group 26 as a CFD test case for examining the effects of grid and turbulence modeling on solution accuracy.

Flow field at design speed and $98 \%$ of maximum flow rate was examined in detail. Three details of the measurements proved to be especially difficult to predict:

(1) Most codes over predicted the overall pressure and temperature ratios and under predicted the efficiency. Predicted pressure ratios varied by nearly $10 \%$ and predicted efficiencies varied by about 6 points.

(2) Most codes failed to predict the total pressure distribution downstream of the rotor below $40 \%$ span. The data shows a region of low total pressure that has been called a "pressure deficit." This terminology implies that there is something wrong with the flow in that region and has prompted much discussion in the literature. Hah, et al. (Ref. 10) suggested that the deficit is due to a corner stall on the rotor suction surface, while Shabbir, et al. (Ref. 16) showed some evidence that it is due to air leaking into the flow path from the gap between the stationary and rotating parts of the hub at the rotor leading edge. Chima, et al. (Ref. 17) suggested that the low total pressure is an intrinsic feature of the rotor that tends to be smeared out by the central-difference schemes used by many CFD codes. 
(3) All codes over predicted the total temperature downstream of the rotor above $90 \%$ span by as much as $17^{\circ} \mathrm{C}$. The discrepancy was generally worse with algebraic turbulence models than with turbulent transport models. It was only mentioned briefly in the AGARD report, but it is either a fundamental problem with CFD methods for turbomachinery or an unrecognized error in the experimental results. In unpublished results provided after the ASME blind test case Strazisar and Suder calculated the total temperature close to the rotor trailing edge using laser measurements of tangential velocity and the Euler turbine equation. These temperatures were similar to the probe measurements further downstream, suggesting that the probe measurements may be correct.

\section{Numerical Procedure}

The H3D code is a multiblock Navier-Stokes analysis code for turbomachinery blade rows. The code solves the full steady and unsteady Navier-Stokes equation in body-fitted grids. A modified two-equation turbulence model is used for turbulence closure. The governing equations are solved with a pressurebased implicit method using a fully conservative control volume approach. A third-order accurate interpolation scheme is used for the discretization of convection terms and central differencing is used for the diffusion terms. The method is of second-order accuracy with smoothly varying grids. For the timedependent terms, an implicit second-order scheme is used and a number of sub-iterations are performed at each time step. Details of the numerical method and applications to transonic flows are given by Hah and Wennerstrom (Ref. 18).

A Large Eddy Simulation (LES) method was applied in the present study. The LES procedure was applied primarily to capture unsteady flow interactions among passage shock, tip leakage vortex, and vortex shedding more realistically. With spatially filtered Navier-Stokes equations, the subgrid-scale stress tensor term must be modeled properly for the closure of the governing equations. A Smagorinskytype eddy-viscosity model was used for the subgrid stress tensor, and the standard dynamic model by Germano et al. (Ref. 19) was applied.

The computational grid for a single blade passage consists of 198 nodes in the blade-to-blade direction, 124 nodes in the spanwise direction, and 560 nodes in the streamwise direction. The inflow boundary was located 6 average blade heights upstream of the rotor leading edge and the outflow boundary was located one blade height from the trailing edge. The rotor tip clearance geometry is accurately represented by 20 nodes in the blade-to-blade direction, 20 nodes in the spanwise direction, and 360 nodes in the streamwise direction. The I-grid topology is used to reduce grid skewness and a single-block grid is used. The computational grid near the rotor is shown in Figure 2. All the computations were performed with NASA's Columbia super computer system, which allows parallel computation with up to 512 processors.

Standard boundary conditions for an isolated rotor were applied at the boundaries of the computational domain. Circumferentially averaged static pressure at the casing was specified to control the mass flow rate. Nonreflecting boundary conditions were applied at the inlet and the exit boundaries.

\section{Overall Flow Structure}

Steady Reynolds averaged Navier-Stokes (RANS) calculations were performed first to obtain compressor characteristics at the design rotor speed. Calculated flow fields at the peak efficiency and the near stall condition are first compared with the measured data. Spanwise distribution of the total pressure rise at the rotor exit was investigated in detail with the calculated flow field. LES simulations were performed at 3 operating conditions to examine whether LES produces improved results along with any additional flow physics. Measured pressure, temperature rise and adiabatic efficiency characteristics of the rotor at the design rotor speed are shown in Figures 3, 4, and 5. The time-averaged LES solutions that are shown in Figures 3 and 4 were obtained by averaging instantaneous solutions over 1000 time steps. 


\section{Flow Field From RANS Simulation}

The choke mass flow was calculated as $20.92 \mathrm{~kg} / \mathrm{s}$ with RANS and $20.91 \mathrm{~kg} / \mathrm{s}$ with LES. The measured choke flow rate is $20.93 \mathrm{~kg} / \mathrm{s}$. Both the RANS and LES calculate the choke mass flow rate within the measurement error range. The corrected mass flow rates in Figures 3, 4, and 5 are nondimensional values with the calculated choke mass. Suder and Celestina (Ref. 4) reported uncertainty range of the measurements in Figures 3, 4, and 5. The uncertainty range was as high as $10 \%$ of the measured value at certain operating point. Results shown in Figures 3, 4, and 5 show that the code calculates more optimistic performance of the compressor than the measurement. Higher pressure rise and higher temperature rise are calculated than the measurements. However, the overall trend is fairly well calculated. The code calculates changes in adiabatic efficiency at different operating conditions fairly well even though the calculated values are higher than the measured values. The measurements show some unusual compressor performance near the choke condition, which can be contributed to some measurement uncertainty. According to various studies, it seems that calculations with some recent turbulence closure models give better agreement with the measurements for this transonic rotor. However, we have not found any specific model which performs universally well for different transonic compressor flow fields. Detailed flow field was surveyed at the flow rate of 0.98 , which was used as blind test case in 1994. Further flow measurements were also conducted at lower mass flow rate at 0.93 . Detailed flow structures at the near peak (flow rate of 0.98) and near stall (flow rate of 0.93) are examined with the numerical solution.

Calculated distributions of total pressure rise at four different mass flow rates are compared with measured values at the mass flow rate of 0.98 in Figure 6. Results in Figure 6 show two clear trends.

(1) The total pressure deficit near the hub is clearly calculated at all mass flow rates.

(2) The pressure rise profile changes significantly with a very small change in mass flow rate.

To study the origin of this pressure deficit near the hub, calculated flow field at $98 \%$ mass flow rate is further examined. Mach number distributions at four spanwise locations are shown in Figure 7.

Calculated Mach number distributions at 70 and $95 \%$ span agrees fairly well with the laser measurement reported by Suder and Celestina (Ref. 4). Mach number distribution at 12\% span indicates flow separation near the training edge at this span. Mach number distribution near the suction surface of the blade is shown in Figure 8. Corresponding velocity vectors are given in Figure 9. Results in Figures 8 and 9 indicate that there is a three-dimensional corner flow separation near the hub. The total pressure deficit near the hub shown in Figure 6 is the results of this corner flow separation. Rotor 37 is a highly loaded transonic compressor rotor. Due to very high aerodynamic loading, the passage shock extends all the way to the hub as shown in Figure 8. The three-dimensional corner separation is due the interaction of the passage shock with the hub boundary layer.

Distributions of total temperature rise at four different mass flow rates are compared with the measurement in Figure 10. The shapes of the temperature profile are very similar at different mass flow rate. However, the absolute values are very sensitive to a small change in mass flow rate. Overall, numerical results agree better near the hub section. Like most previously reported CFD results, the code predicts higher temperature rise toward the casing. Compared to published results from different codes, the calculated temperature rise agrees better with the measurement. As shown in this section, the flow field in this highly loaded compressor is very sensitive to a small change in mass flow rate. Further measurements at $60 \%$ rotor design speed by Suder and Celestina (Ref. 4 ) show that the dip in the total pressure distribution in Figure 6 disappears. The code calculates no large corner stall at $60 \%$ rotor design speed and calculated total pressure rise profile matches very well with the measurements as reported by Hah and Loellbach (Ref. 10).

Calculated total pressure and total temperature distributions at the measurement station 4 at near stall condition are compared with the measurement in Figure 11. Again calculation shows hub corners tall at this operating condition and the profile agrees with the measurement. Also the calculation predicts higher 
pressure rise near the tip section compared to the measurement. As shown in Figures 7 and 11, the current RANS simulation calculates higher pressure rise near the tip than the measurement. This might be due to the fact that the current RANS does not model the interaction between the passage shock and the tip clearance vortex accurately. On the other hand, the RANS calculates pressure rise near the hub section fairly well.

Just ahead of rotor leading edge, there is a small gap between the stationary part of the hub and the rotating part of the hub, and there might be a small amount of leakage flow coming from this gap. As is widely known, the flow field in a transonic compressor is extremely sensitive to a small change in the geometry and flow condition. Shabbir et al. (Ref. 16) did numerical study on the effects of this leakage flow on the exit profile of total pressure rise. They assumed variety of flow profiles coming out of the gap as no measured data are available. Their study indicated that the total pressure rise can be altered quite bit even with about $0.25 \%$ of total mass flow. As mentioned before, the total pressure rise at the rotor exit does not show any deficit near the hub at $60 \%$ rotor speed according to measurements as well as the calculation. If the pressure rise deficit near the hub at $100 \%$ rotor design speed is due to the hub leakage flow, further explanation is required why the hub deficit disappears at $60 \%$ rotor design speed.

\section{Flow Field From LES Simulation}

Large Eddy Simulation was applied to see whether LES can simulate flow field better compared to RANS. As observed from the RANS simulation with the currently applied turbulence model, flow field near the casing is not well represented with the RANS. Flow interactions among tip leakage vortex, passage shock, and vortex shedding in a transonic compressor are inherently unsteady. Although steady RANS calculates certain aspect of average flow field, detailed unsteady flow mechanisms are difficult to calculate realistically. LES was applied to calculate flow fields at the choke condition, near the peak efficiency condition and near stall condition. The choke flow rate from the LES is $20.91 \mathrm{~kg} / \mathrm{s}$. Figure 12 shows an instantaneous distribution of Mach number at mid span at near peak efficiency. Instantaneous velocity vectors are given in Figure 13. Shock induced boundary layer separation and resulting vortex shedding are well calculated. Mach number distributions from the averaged LES simulation at $95 \%$ span are shown in Figure 14 along with the measured values. The Mach number distributions from the averaged LES solution matches much better with the measurement than RANS results shown in Figure 7. RANS calculation with conventional turbulence closure scheme do not simulate interaction between the passage shock and the tip leakage vortex accurately. On the other hand, LES simulates this interaction much more realistically and the results agree very well with the measurement. Changes in Mach number distribution at the blade tip at near stall are shown in Figures 15 and 16 shows changes in velocity vectors at the blade tip for the near stall condition. As shown in Figures 15 and 16, the flow field becomes unsteady due to interactions among the passage shock, tip leakage vortex, and vortex shedding. Due to this self-induced unsteadiness, flow incidence at the leading edge changes as much as $5^{\circ}$ and the tip core vortex oscillates significantly.

Calculated distributions of total pressure and total temperature at the rotor exit with LES are shown in Figures 17 and 18. Compared to the results with the RANS simulation, it looks like the LES removed some over prediction of pressure and temperature rise near the casing by RANS. As the results in Figure 17 indicate, the dip in total pressure rise near the hub is calculated also with the LES. Instantaneous velocity vectors near the suction side from LES simulation are shown in Figure 19. Hub corner stall is clearly shown in Figure 19 as was the case with RANS simulation. 


\section{Concluding Remarks}

The H3D turbomachinery analysis code was used to predict the performance of Rotor 37 transonic compressor rotor. Both RANS and LES modes were used to investigate detailed flow features. RANS calculations were performed to examine how the H3D code with the applied turbulence closure calculates the measured compressor performance. Although the code predicts more optimistic aerodynamic performance than measurement, many aspects of this highly loaded compressor flow field are fairly well calculated if difficulty and uncertainty of measurements are considered. The RANS calculates total pressure deficit near the hub very well even with the currently applied turbulence closure. Also, total temperature rise near the casing is calculated fairly well compared to previously published CFD results. LES simulation shows better agreement with the measurements especially near the casing. This might be due to the fact that the LES can simulate flow interactions among passage shock, tip leakage vortex, and vortex shedding correctly. The LES seems to represent unsteady flow interactions much more realistically. Practical application of LES to calculate unsteady flow fields in transonic compressors requires further developments and validations. However, some early results presented in the current study show very promising aspects of the LES.

\section{References}

1. Reid, L. and Moore, R.D., "Design and Overall Performance of Four Highly-Loaded, High Speed Inlet Stages for an Advanced, High Pressure Ratio Core Compressor," NASA TP-1337, 1978.

2. Reid, L. and Moore, R.D., "Performance of a Single-Stage Axial-Flow Transonic Compressor With Rotor and Stator Aspect Ratios of 1.19 and 1.26, Respectively, and With Design Pressure Ratio of 1.82, NASA TP-1338, 1978.

3. Reid, L. and Moore, R.D., "Experimental Study of Low Aspect Ratio Compressor Blading," ASME Paper 80-GT-6, Mar. 1980.

4. Suder, K.L., and Celestina, M.L., "Experimental and Computational Investigation of the Tip Clearance Flow in a Transonic Axial Compressor Rotor," NASA TM-106711, 1994.

5. Suder, K.L., Chima, R.V., Strazisar, A.J., and Roberts, W.B., "The Effect of Adding Roughness and Thickness to a Transonic Axial Compressor Rotor," ASME J. Turbomachinery, vol. 117, Oct. 1995, pp. 491-505.

6. Dunham, J. ed. "CFD Validation for Propulsion System Components," AGARD Advisory Report 355, AGARD, Neuilly-Sur-Seine, France, May, 1998.

7. Dunham, J. and Meauzé, "An AGARD Working Group Study of 3-D Navier-Stokes Codes Applied to Single Turbomachinery Blade Rows," ASME Paper 98-GT-50, June, 1998.

8. Hah, C., 1984, "A Navier-Stokes Analysis of Three-Dimensional Flows Inside Turbine Blade Rows at Design and Off-Design Conditions," ASME Journal of Engineering for Gas Turbines and Power, vol. 106, pp. 421-429.

9. Hah, C., 1986, “A Numerical modeling of Endwall and Tip-Clearance Flow of an Isolated Compressor Rotor," ASME Journal of Engineering for Gas Turbines and Power, vol. 108, pp. 15-21.

10. Hah, C. and Loellbach, J., "Development of Hub Corner Stall and its Influence on the Performance of Axial Compressor Blade Rows," ASME Paper 97-GT-42, June, 1977.

11. Hah, C. and Reid, L., 1992, "A Viscous Flow Study of Shock-Boundary Layer Interaction, Radial Transport, and Wake Development in a Transonic Compressor," ASME Journal of Turbomachinery, vol. 114, no. 2, pp. 538-547.

12. Hah, C., Copenhaver, W.W., and Puterbaugh, S.L., 1993, "Three-Dimensional Flow Phenomena in a Transonic High-Throughflow, Axial-Flow Compressor Stage," ASME Journal of Turbomachinery, vol. 115 , no. 2, pp. 240-248.

13. Hah, C., Rabe, D.C., Sullivan, T.J., and Wadia, A.R., 1996, "Effects of Inlet Distortion on the Flow Field in a Transonic Compressor Rotor," ASME Journal of Turbomachinery, vol. 120, no. 2, pp. 233246. 
14. Puterbaugh, S.L., Copenhaver, W.W, Hah, C., and Wennerstrom, A.J., 1997, “A Three-Dimensional Shock Loss Model applied to an AFT-Swept, Transonic Compressor Rotor," ASME Journal of Turbomachinery, vol. 119, no. 3, pp. 452-459.

15. Hah, C. and Y. Lee, 2007, "Unsteady Pressure Field Due to Interactions Among Tip Leakage Vortex, Trailing Edge Vortex, and Vortex Shedding in a Ducted Propeller," ASME Paper, GT2007-27407.

16. Shabbir, A., Celestina, M.L., Adamczyk, J.J., and Strazisar, A.J., "The Effect of Hub Leakage Flow on Two High Speed Axial Compressor Rotors," ASME Paper 97-GT-346, June, 1997.

17. Chima, R.V. and Liou, M.-S., "Comparison of the AUSM ${ }^{+}$and H-CUSP Schemes for Turbomachinery Applications," AIAA Paper AIAA-2003-4120. Also NASA/TM-2003-212457.

18. Hah, C. and Wennerstrom, A.J., 1991, "Three-Dimensional Flow Fields Inside a Transonic Compressor With Swept Blades," ASME Journal of Turbomachinery, vol. 113, no. 1, pp. 241-251.

19. Germano, M., Piomelli, U., Moin, P., and Cabot, W.H., 1991, "A Dynamic Subgrid-Scale EddyViscosity Model," Journal of Fluid Mechanics, vol. A3, pp. 170-176.

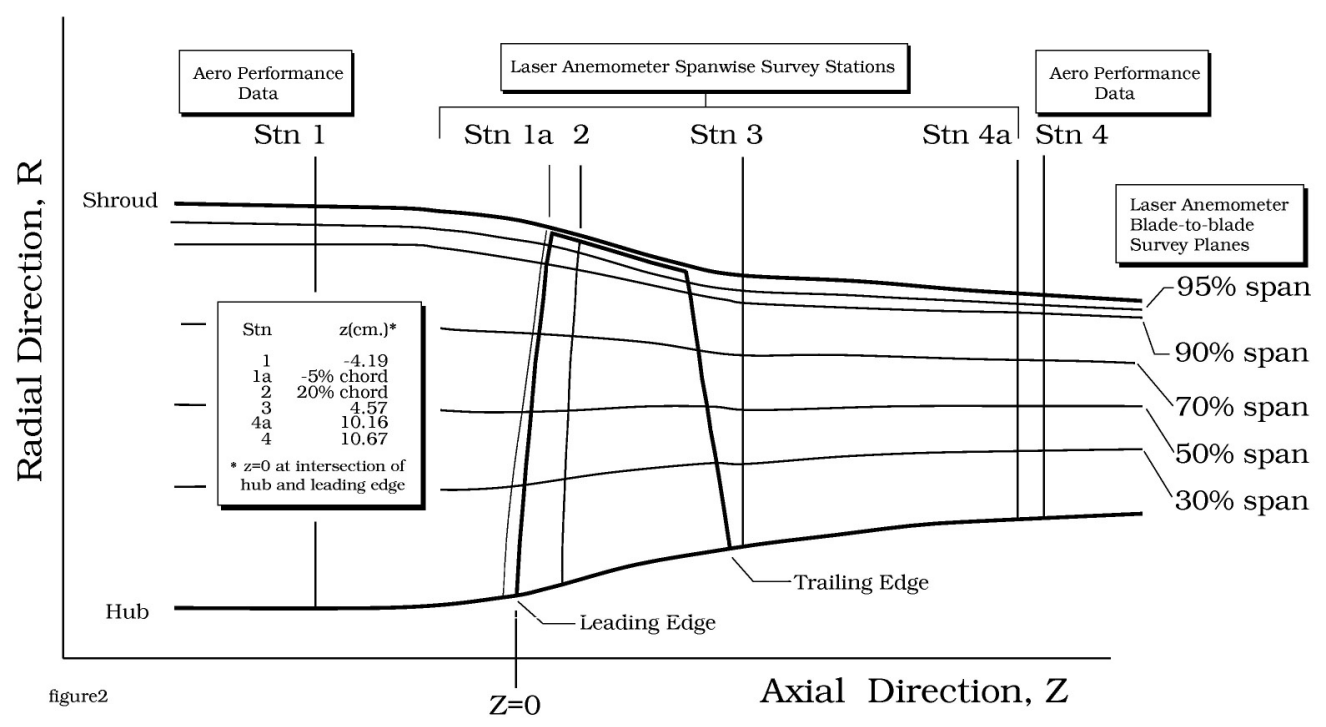

Figure 1.- Rotor 37 cross section and measurement stations.

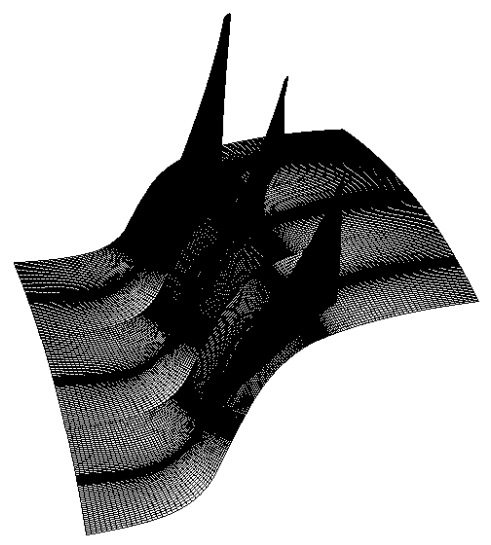

Figure 2.-Computational grid near the Rotor 37. 


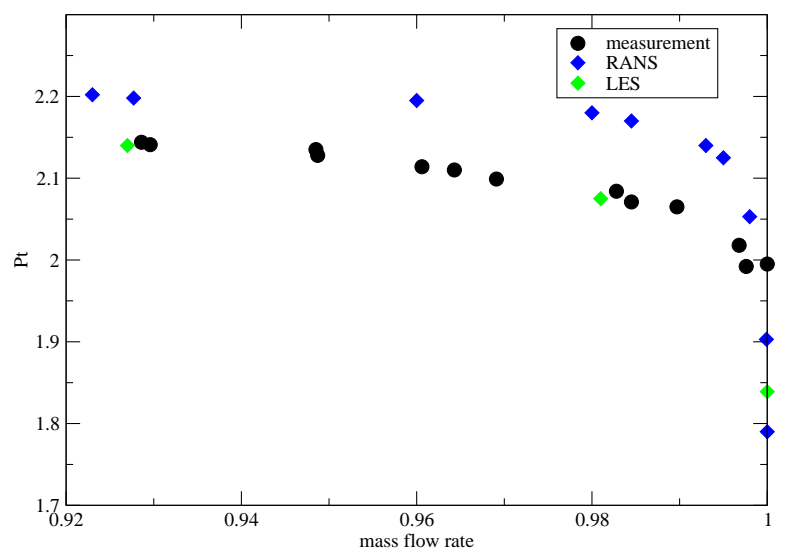

Figure 3.-Pressure rise characteristics of the rotor at design rotor speed.

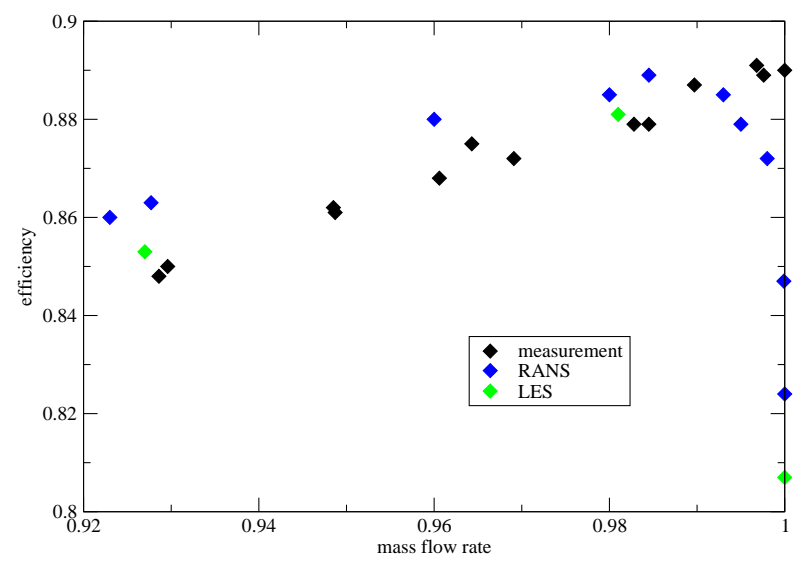

Figure 5.-Adiabatic efficiency of the rotor at design rotor speed.

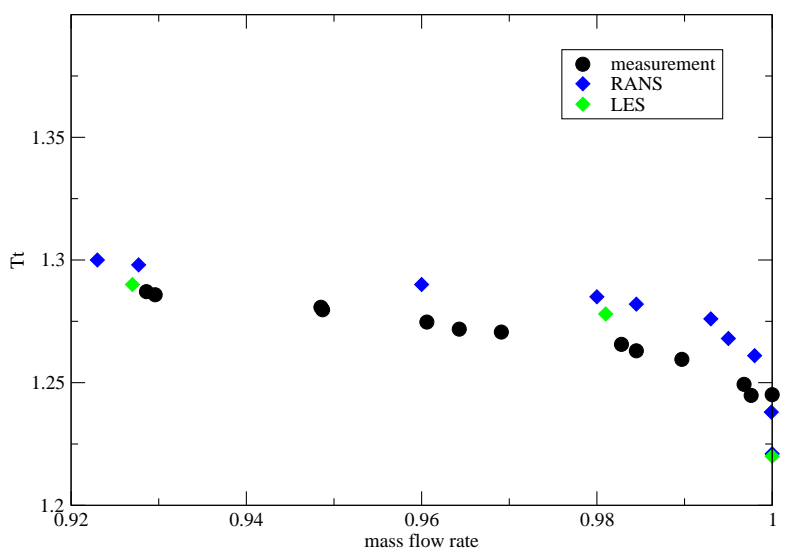

Figure 4.-Temperature rise characteristics of the rotor at design rotor speed.

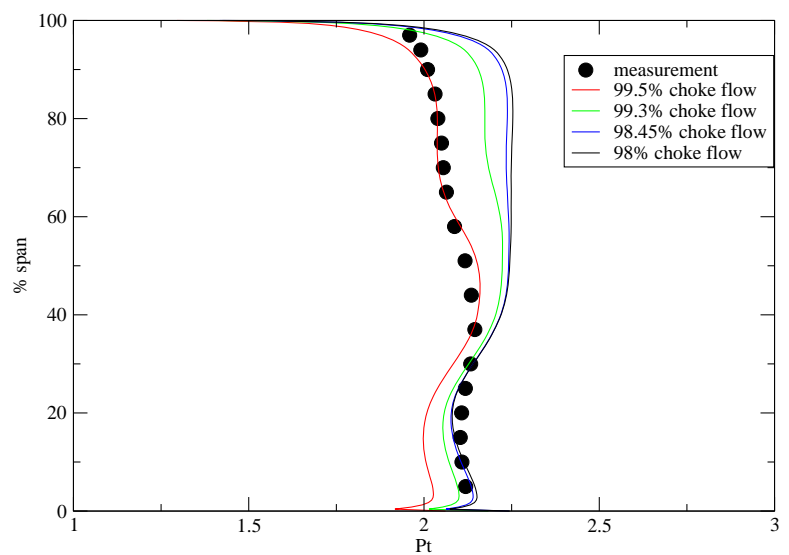

Figure 6.-Comparison of total pressure distribution downstream of Rotor 37. 


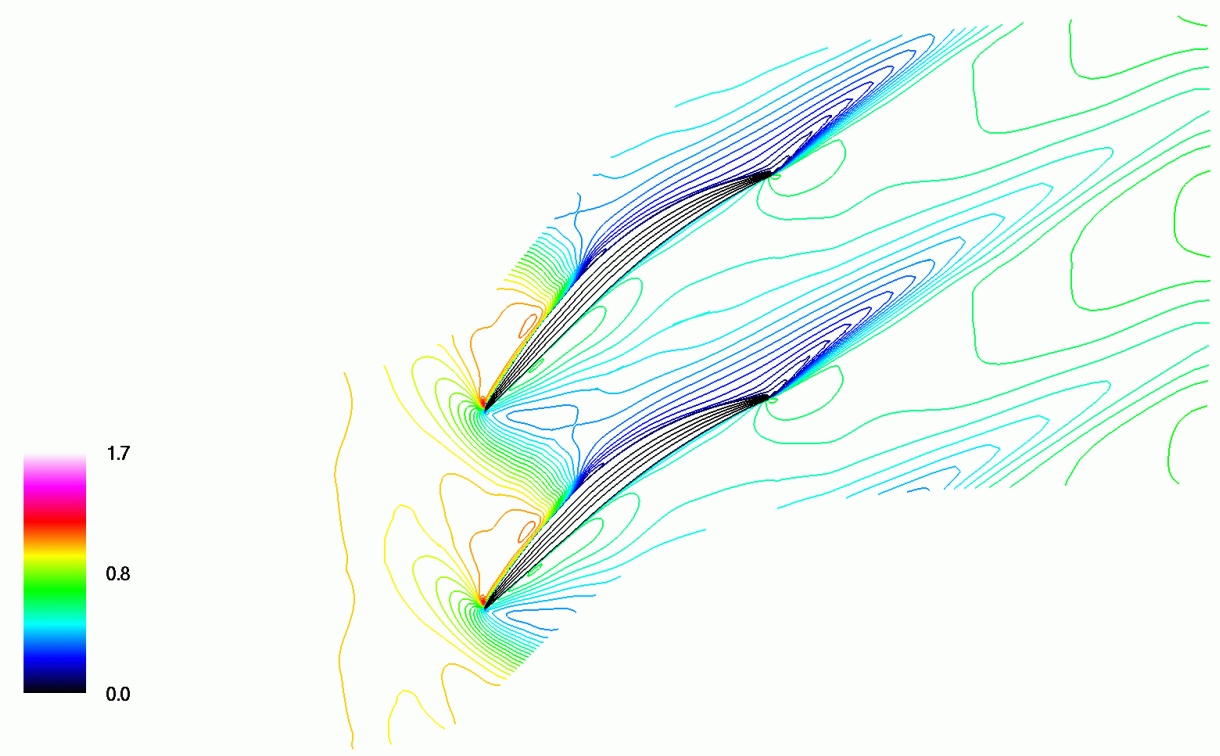

Figure 7(a).-Mach number distribution at 5\% span, near peak efficiency, rotor design speed.

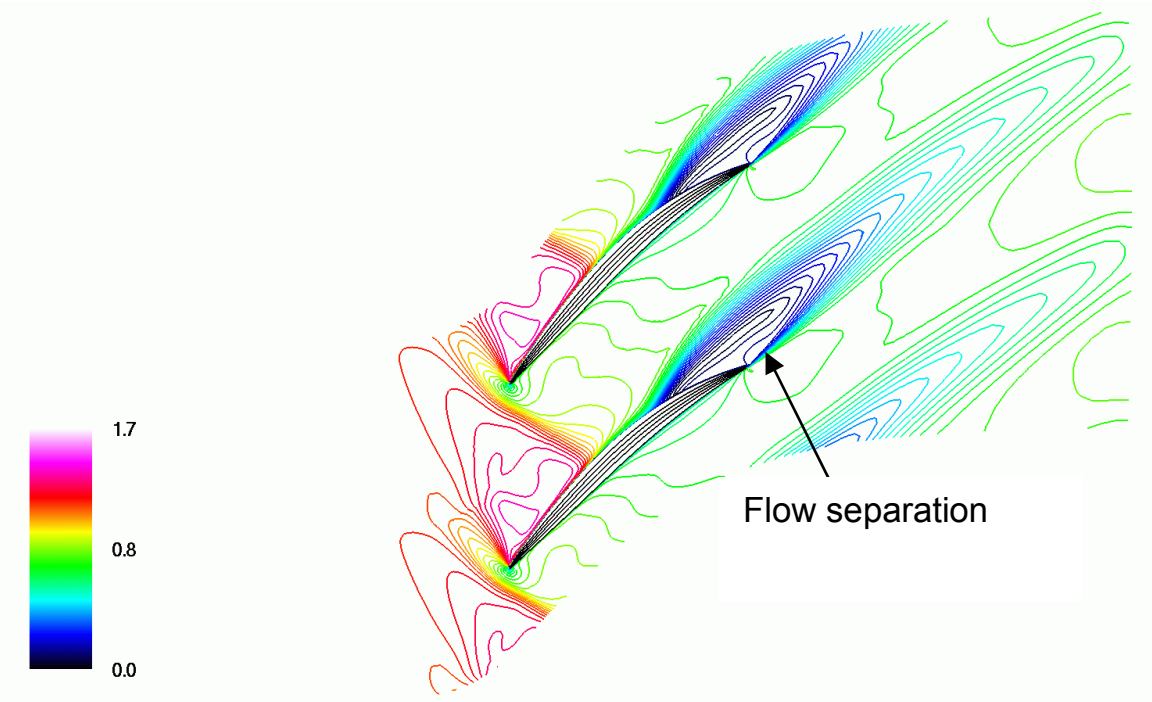

Figure 7(b).--Mach number distribution at $12 \%$ span, near peak efficiency, rotor design speed. 


$$
\frac{14}{14}
$$




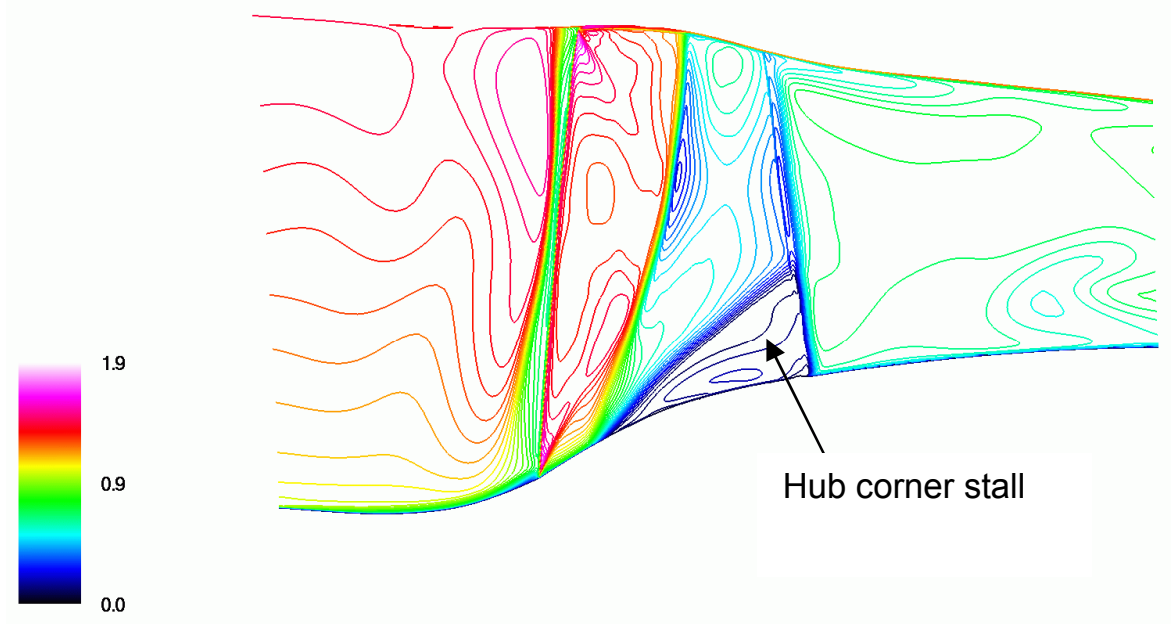

Figure 8.-Mach number distribution near the suction surface, near peak efficiency, rotor design speed.

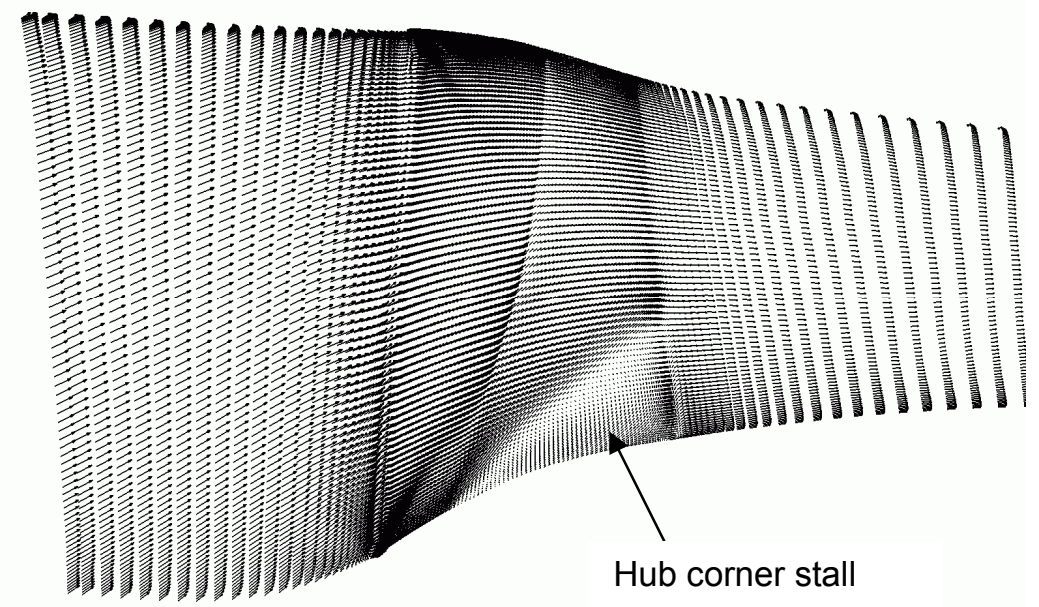

Figure 9.-Velocity vectors near the suction surface, near peak efficiency, rotor design speed. 


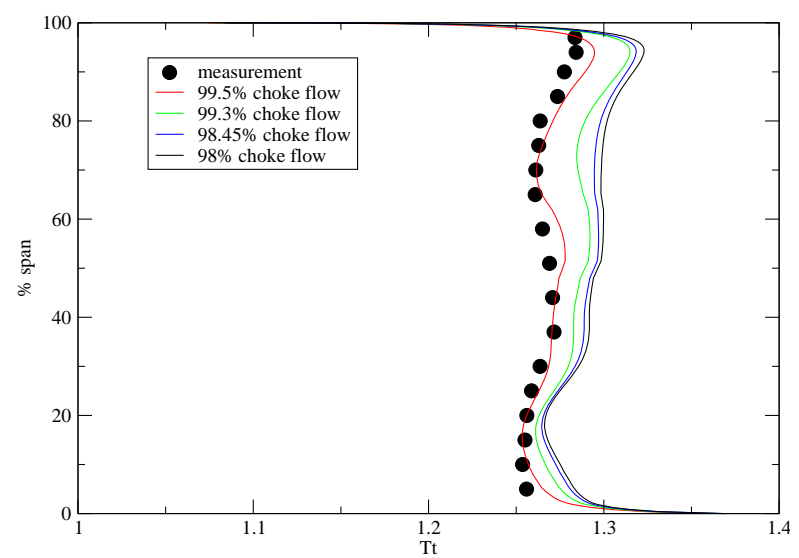

Figure 10.-Comparison of total temperature distribution downstream of Rotor 37.

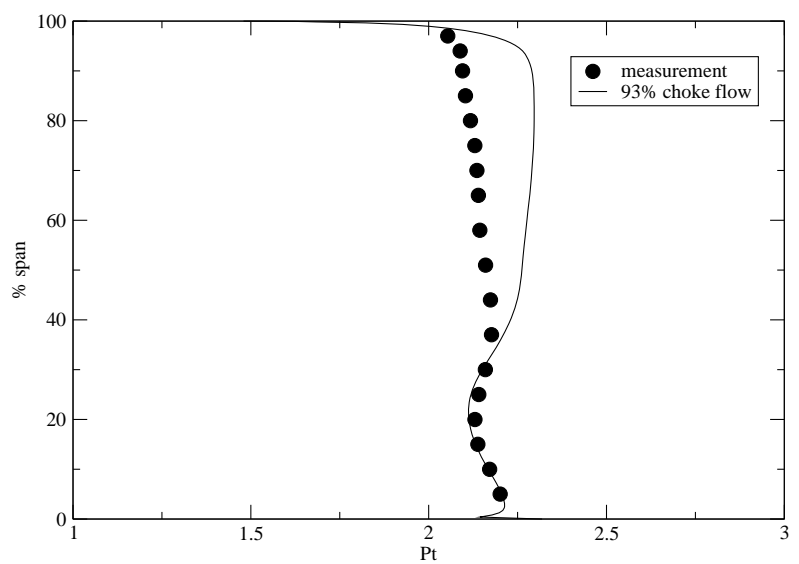

Figure 11(a).-Comparison of total pressure rise downstream of Rotor 37, near stall, rotor design speed.

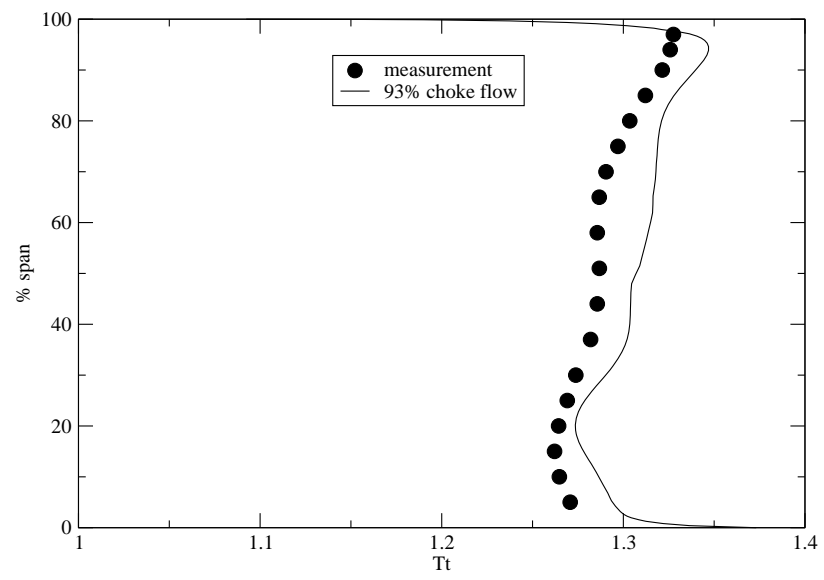

Figure 11(b).-Comparison of total temperature distribution downstream of Rotor 37, near stall, rotor design speed. 


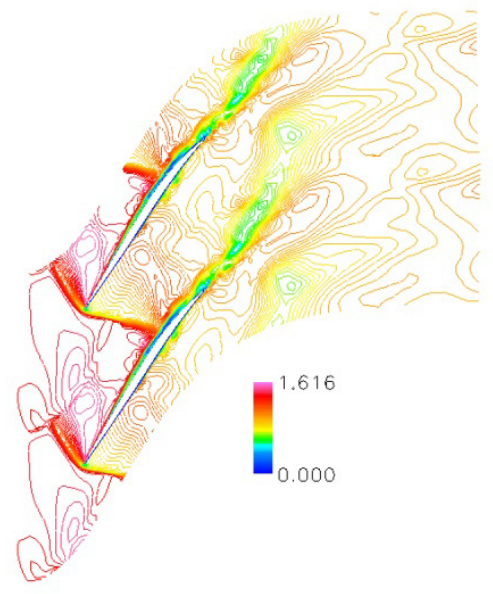

Figure 12.-Instantaneous Mach number distribution at mid-span, near peak efficiency from LES.

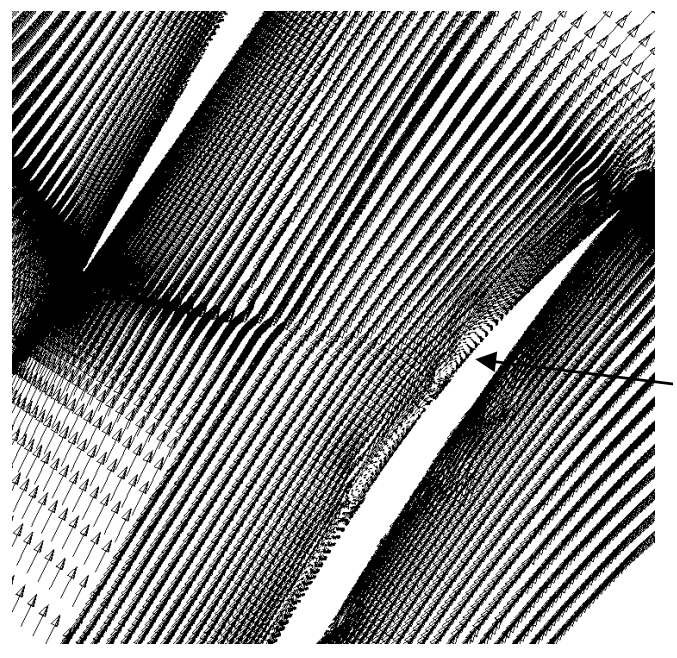

Shock induced flow separation

Figure 13. - Instantaneous velocity vectors at mid-span, near peak efficiency from LES. 


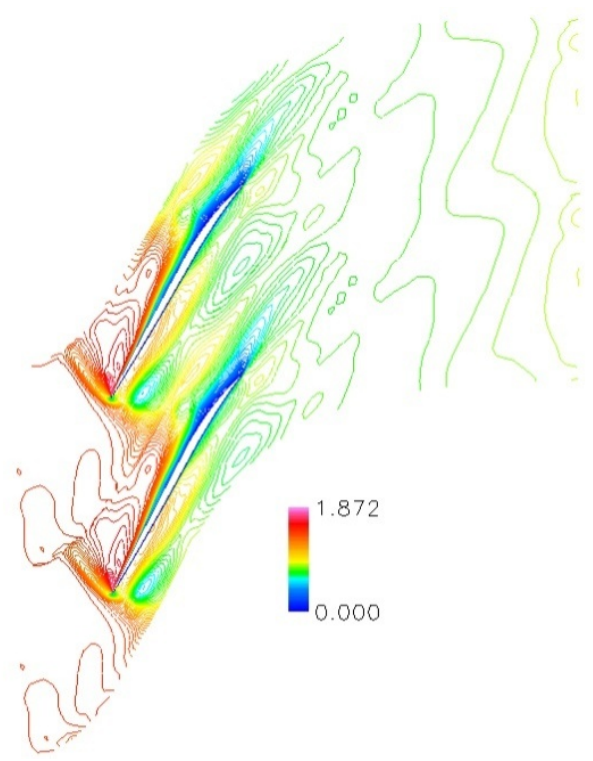

Figure 14(a).-Calculated time-averaged Mach number distribution at $95 \%$ span, near peak efficiency from LES.

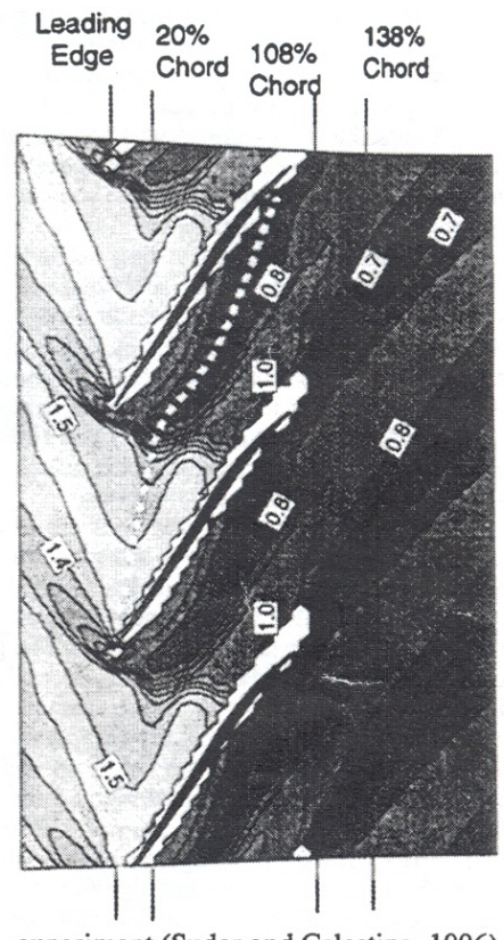

experiment (Suder and Celestina, 1996)

(b) $95 \%$ span

Figure 14(b).--Measured Mach number distribution at $95 \%$ span, near peak efficiency. 


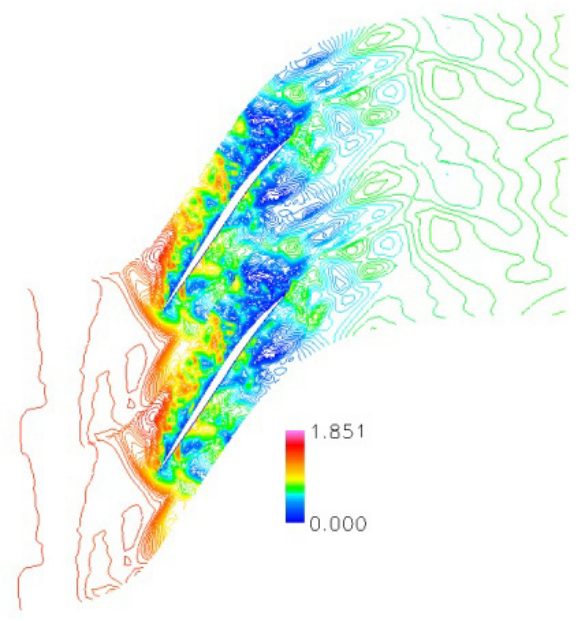

Figure 15(a).-Instantaneous Mach number distribution at time 1, blade tip and near stall condition.

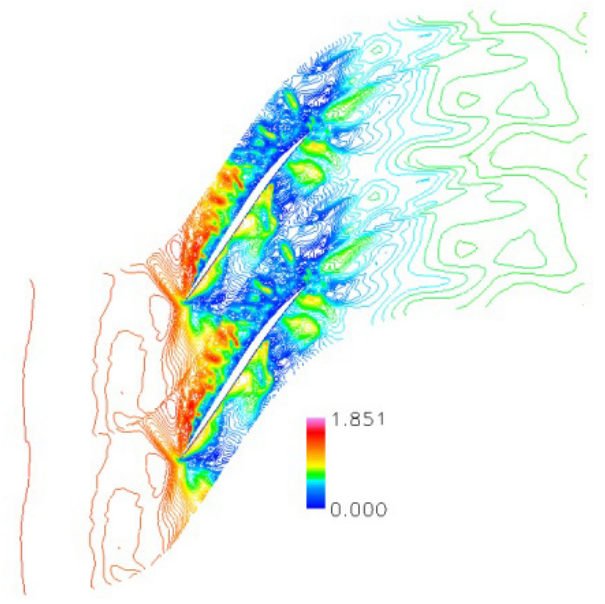

Figure 15(b).-Instantaneous Mach number distribution at time 2, blade tip and near stall condition.

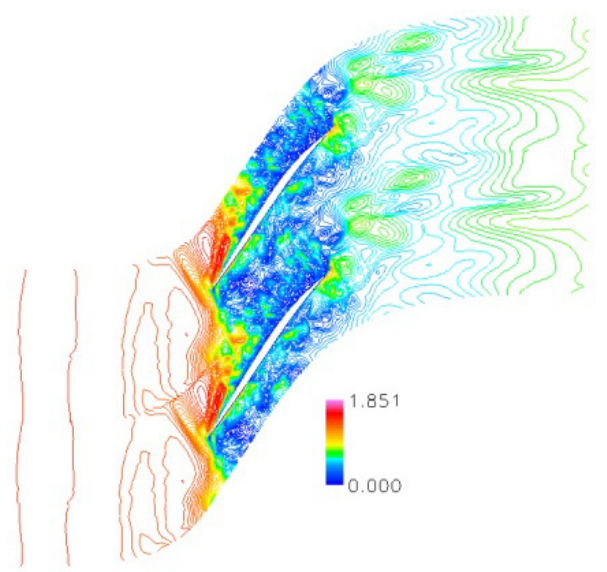

Figure 15(c).-Instantaneous Mach number distribution at time 3 , blade tip and near stall condition. 


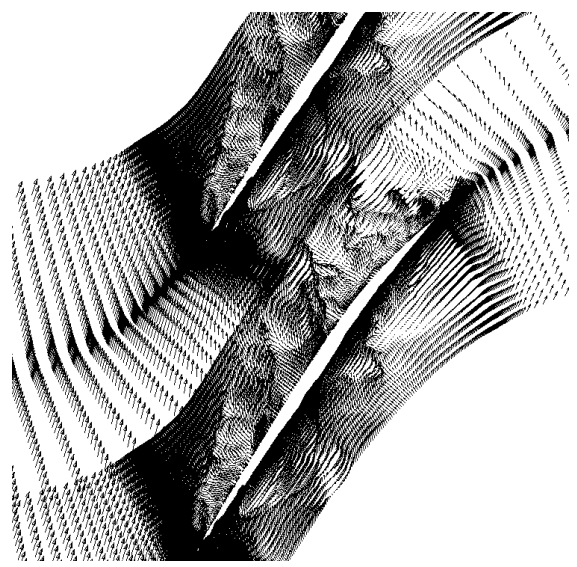

Figure 16(a).--Instantaneous velocity vectors at time step 1 , blade tip and near stall condition.

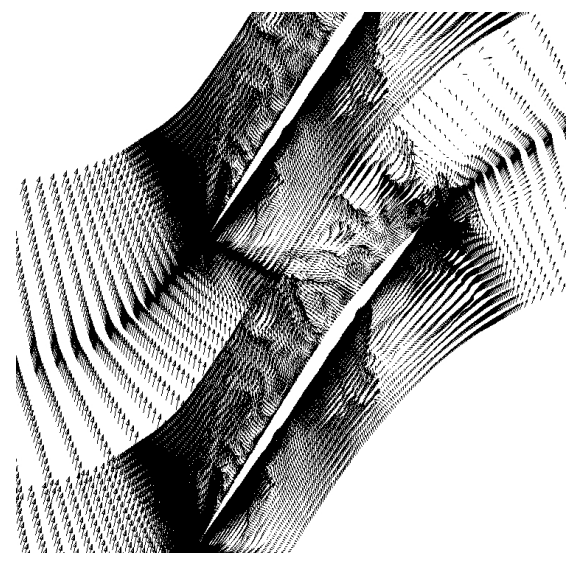

Figure 16(b).--Instantaneous velocity vectors at time step 2 , blade tip and near stall condition.

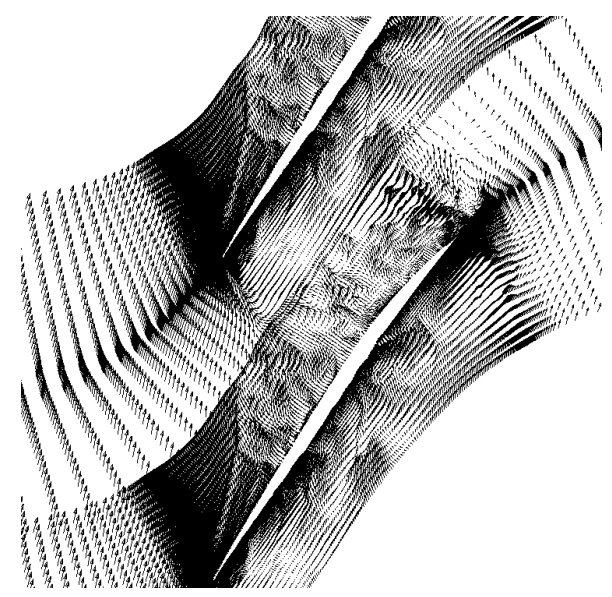

Figure 16(c).--Instantaneous velocity vectors at time step 3 , blade tip and near stall condition. 


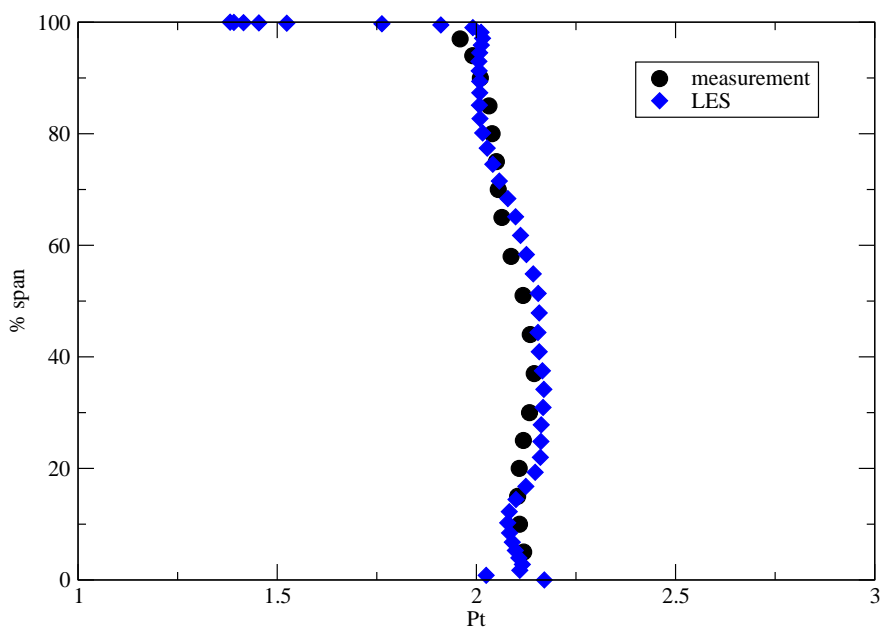

of Rotor 37 near peak efficiency.

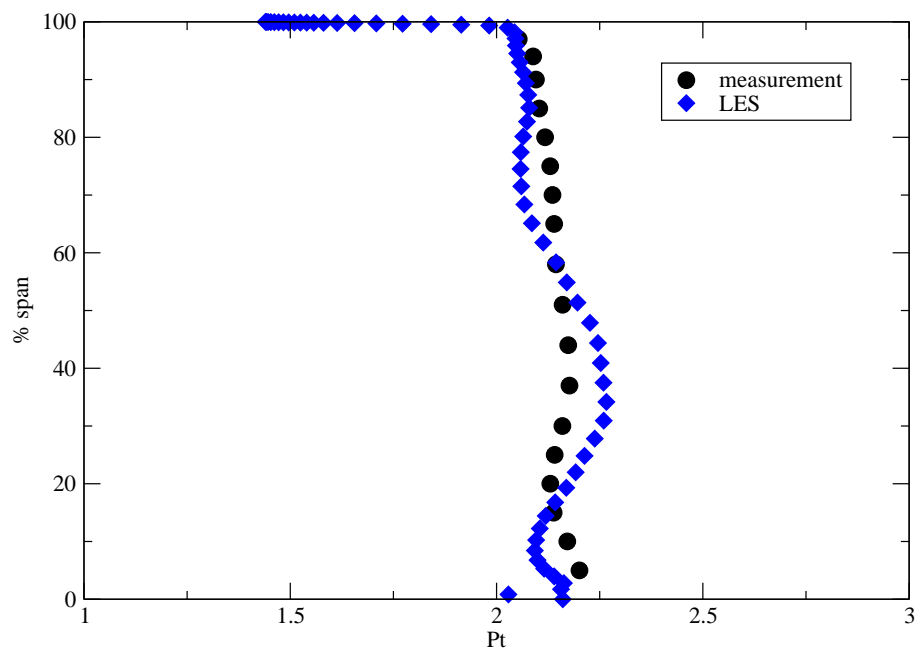

Figure 17(b).-Comparison of total pressure profile downstream of Rotor 37 near stall condition. 


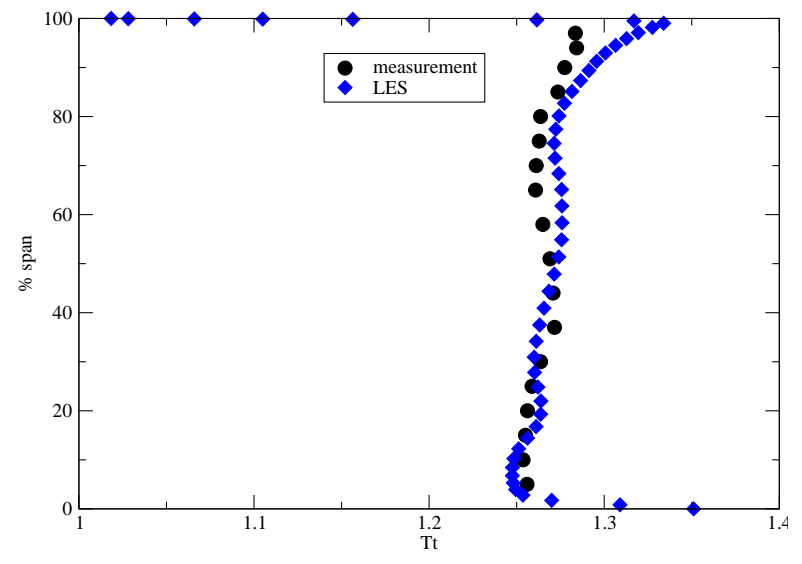

Figure 18(a).-Comparison of total temperature profile downstream of Rotor 37 near peak efficiency.

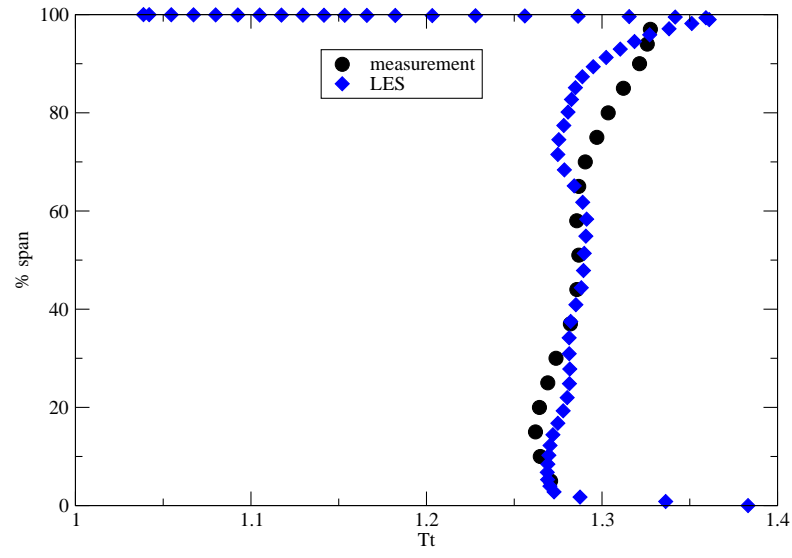

Figure 18(b).-Comparison of total temperature profile downstream of Rotor 37 near stall condition.

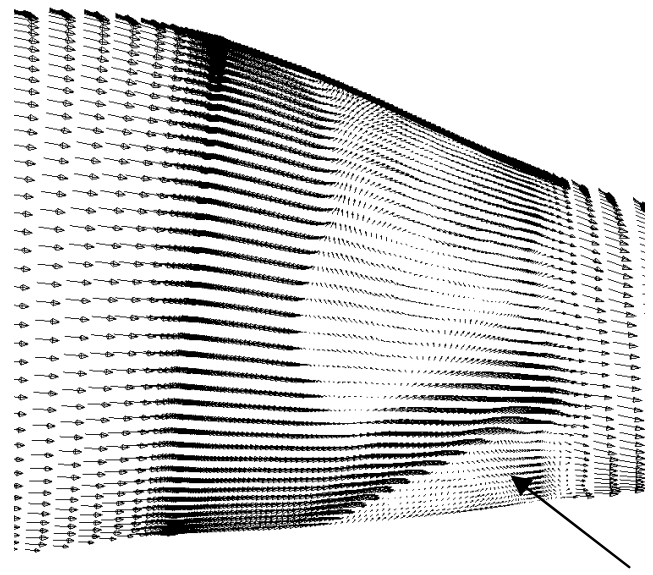

Hub corner stall

Figure 19.-Instantaneous velocity vectors near suction surface, near peak efficiency from LES. 


\begin{tabular}{|c|c|c|c|c|c|}
\hline \multicolumn{5}{|c|}{ REPORT DOCUMENTATION PAGE } & $\begin{array}{c}\text { Form Approved } \\
\text { OMB No. 0704-0188 }\end{array}$ \\
\hline \multicolumn{6}{|c|}{ 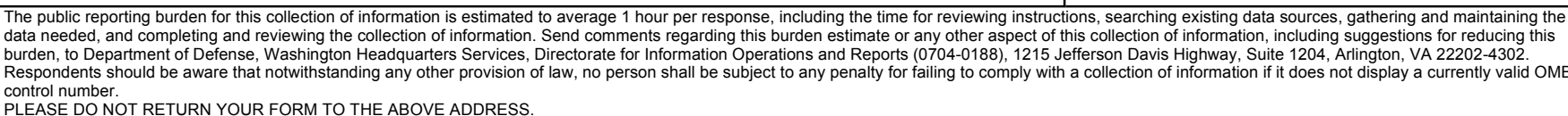 } \\
\hline \multicolumn{2}{|c|}{$\begin{array}{l}\text { 1. REPORT DATE (DD-MM-YYYY) } \\
01-09-2009\end{array}$} & \multicolumn{3}{|c|}{$\begin{array}{l}\text { 2. REPORT TYPE } \\
\text { Technical Memorandum }\end{array}$} & 3. DATES COVERED (From - To) \\
\hline \multirow{3}{*}{\multicolumn{5}{|c|}{$\begin{array}{l}\text { 4. TITLE AND SUBTITLE } \\
\text { Large Eddy Simulation of Transonic Flow Field in NASA Rotor } 37\end{array}$}} & 5a. CONTRACT NUMBER \\
\hline & & & & & 5b. GRANT NUMBER \\
\hline & & & & & 5c. PROGRAM ELEMENT NUMBER \\
\hline \multirow{3}{*}{\multicolumn{4}{|c|}{$\begin{array}{l}\text { 6. AUTHOR(S) } \\
\text { Hah, Chunill }\end{array}$}} & & 5d. PROJECT NUMBER \\
\hline & & & & & 5e. TASK NUMBER \\
\hline & & & & & $\begin{array}{l}\text { 5f. WORK UNIT NUMBER } \\
\text { WBS 561581.02.08.03.21.02 }\end{array}$ \\
\hline \multicolumn{5}{|c|}{$\begin{array}{l}\text { 7. PERFORMING ORGANIZATION NAME(S) AND ADDRESS(ES) } \\
\text { National Aeronautics and Space Administration } \\
\text { John H. Glenn Research Center at Lewis Field } \\
\text { Cleveland, Ohio 44135-3191 }\end{array}$} & $\begin{array}{l}\text { 8. PERFORMING ORGANIZATION } \\
\text { REPORT NUMBER } \\
\text { E-16939 }\end{array}$ \\
\hline \multirow{2}{*}{\multicolumn{5}{|c|}{$\begin{array}{l}\text { 9. SPONSORING/MONITORING AGENCY NAME(S) AND ADDRESS(ES) } \\
\text { National Aeronautics and Space Administration } \\
\text { Washington, DC 20546-0001 }\end{array}$}} & $\begin{array}{l}\text { 10. SPONSORING/MONITOR'S } \\
\text { ACRONYM(S) } \\
\text { NASA }\end{array}$ \\
\hline & & & & & $\begin{array}{l}\text { 11. SPONSORING/MONITORING } \\
\text { REPORT NUMBER } \\
\text { NASA/TM-2009-215627 }\end{array}$ \\
\hline \multicolumn{6}{|c|}{$\begin{array}{l}\text { 12. DISTRIBUTION/AVAILABILITY STATEMENT } \\
\text { Unclassified-Unlimited } \\
\text { Subject Category: } 07 \\
\text { Available electronically at http://gltrs.grc.nasa.gov } \\
\text { This publication is available from the NASA Center for AeroSpace Information, 443-757-5802 }\end{array}$} \\
\hline \multicolumn{6}{|c|}{ 13. SUPPLEMENTARY NOTES } \\
\hline \multicolumn{6}{|c|}{$\begin{array}{l}\text { 14. ABSTRACT } \\
\text { The current paper reports on numerical investigations on the flow characteristics in a transonic axial compressor, NASA Rotor } 37 \text {. The flow } \\
\text { field was used previously as a CFD blind test case conducted by American Society of Mechanical Engineers in 1994. Since the CFD blind- } \\
\text { test exercise, many numerical studies on the flow field in the NASA Rotor } 37 \text { have been reported. Although steady improvements have been } \\
\text { reported in both numerical procedure and turbulence closure, it is believed that all the important aspects of the flow field have not been fully } \\
\text { explained with numerical studies based on the Reynolds Averaged Navier-Stokes (RANS) solution. Experimental data show large dip in } \\
\text { total pressure distribution near the hub at downstream of the rotor at } 100 \% \text { rotor speed. Most original numerical solutions from the blind test } \\
\text { exercise did not predict this total pressure deficit correctly. This total pressure deficit at the rotor exit was attributed to a hub corner flow } \\
\text { separation by the author. Several subsequent numerical studies with different turbulence closure model also calculated this dip in total } \\
\text { pressure rise. Also, several studies attributed this total pressure deficit to a small leakage flow coming from the hub in the test article. As the } \\
\text { experimental study cannot be repeated, either explanation cannot be validated. The primary purpose of the current investigation is to } \\
\text { investigate the transonic flow field with both RANS and a Large Eddy Simulation (LES). The RANS approach gives similar results } \\
\text { presented at the original blind test exercise. Although the RANS calculates higher overall total pressure rise, the total pressure deficit near } \\
\text { the hub is calculated correctly. The numerical solution shows that the total pressure deficit is due to a hub corner flow separation. The } \\
\text { calculated pressure rise from the LES agrees better with the measured total pressure rise especially near the casing area where the passage } \\
\text { shock interacts with the tip clearance vortex and flow becomes unsteady due to this interaction. The LES simulation also calculates the total } \\
\text { pressure rise deficit near the hub and it agrees well with the measured data. }\end{array}$} \\
\hline \multicolumn{6}{|c|}{$\begin{array}{l}\text { 15. SUBJECT TERMS } \\
\text { Transonic; Shock; Compressor }\end{array}$} \\
\hline \multicolumn{3}{|c|}{ 16. SECURITY CLASSIFICATION OF: } & $\begin{array}{l}\text { 17. LIMITATION OF } \\
\text { ABSTRACT }\end{array}$ & $\begin{array}{l}\text { 18. NUMBER } \\
\text { OF }\end{array}$ & $\begin{array}{l}\text { 19a. NAME OF RESPONSIBLE PERSON } \\
\text { STI Help Desk (email:help@sti.nasa.gov) }\end{array}$ \\
\hline $\begin{array}{l}\text { a. REPORT } \\
\text { U }\end{array}$ & $\begin{array}{l}\text { b. ABSTRACT } \\
\text { U }\end{array}$ & $\begin{array}{l}\text { c. THIS } \\
\text { PAGE } \\
\text { U }\end{array}$ & UU & $\begin{array}{c}\text { PAGES } \\
24\end{array}$ & $\begin{array}{l}\text { 19b. TELEPHONE NUMBER (include area code) } \\
443-757-5802\end{array}$ \\
\hline
\end{tabular}



